Int. J. Electrochem. Sci., 13 (2018) $4891-4900$

Mini Review

\title{
Material Corrosion in Molten Fluoride Salts
}

Yanli Wang ${ }^{1}$, Shenghua Zhang ${ }^{2, *}$, Xiaohong $\mathrm{Ji}^{1}$, Ping Wang ${ }^{1}$, Weihua $\mathrm{Li}^{1,3}$

${ }^{1}$ School of Chemistry and Chemical Engineering, Guangxi University, Nanning, 530004, P R China.

${ }^{2}$ School of Resources, Environment and Materials, Guangxi University, Nanning, 530004, P R China.

${ }^{3}$ School of Chemical Engineering and Technology, Sun Yat-sen University.

*E-mail: wyl15104008565@126.com

doi: $10.20964 / 2018.05 .33$

Received: 25 January 2018 / Accepted: 7 March 2018 / Published: 10 April 2018

Molten Salt Reactors (MSRs) have received worldwide attention due to its favorable economics, fueled utilization and safety characteristics. The fuel and coolant of MSRs are both molten fluoride salts. The subsequent molten salt induced structural material corrosion problem is a bottleneck during the development of MSRs, and thus has been investigated extensively. In this paper, the influence factors and mechanisms of material corrosion in molten fluoride salts are fully discussed.

Keywords: Molten fluoride salts, Mechanism, Corrosion, Molten salt reactors.

\section{$\underline{\text { FULL TEXT }}$}

(C) 2018 The Authors. Published by ESG (www.electrochemsci.org). This article is an open access article distributed under the terms and conditions of the Creative Commons Attribution license (http://creativecommons.org/licenses/by/4.0/). 